\title{
Synthesis and Characterization of Novel Polyarylates from 2,5-Bis(4-hydroxyphenyl)-3,4-diphenylthiophene and Various Aromatic Dicarboxylic Acids
}

\author{
Hwa-Jin Jeong, Ken Iwasaki, Masa-aki Kakimoto, \\ and Yoshio IMAI* \\ Department of Organic and Polymeric Mateials, Tokyo Institute of Technology, \\ Meguro-ku, Tokyo 152, Japan
}

(Received October 19, 1993)

\begin{abstract}
A new tetraphenylated heterocyclic diol, 2,5-bis(4-hydroxyphenyl)-3,4-diphenylthiophene, was synthesized in three steps starting from 4-methoxydeoxybenzoin. The tetraphenylthiophene-containing polyarylates having inherent viscosities of $0.29-0.84 \mathrm{dlg}^{-1}$ were prepared by the high temperature solution polycondensation of the diol with various aromatic dicarboxylic acid chlorides. All the polyarylates were crystalline or semicrystalline, and the crystalline polyarylates were quite insoluble in organic solvents, while the others dissolved readily in a variety of solvents including $\mathrm{N}$-methyl-2-pyrrolidone and sym-tetrachloroethane. These polymers had glass transition temperatures in the range of $209-260^{\circ} \mathrm{C}$, with no weight loss below $400^{\circ} \mathrm{C}$ in both air and nitrogen atmospheres.
\end{abstract}

KEY WORDS High Temperature Polyarylates / Tetraphenylthiophenediol / Solubility / Crystallinity / Thermal Behavior /

Polyarylates have been known for their usefulness in meeting the high performance requirements for various applications. ${ }^{1,2} \mathrm{We}$ already reported that the introduction of pendant phenyl groups through tetraphenylthiophene, ${ }^{3}$ tetraphenylfuran, ${ }^{4}$ and tetraphenylpyrrole units ${ }^{5}$ into polyarylate backbones afforded organic-soluble polymers with high glass transition temperatures. The incorporation of these tetraphenylated heterocylic moieties were also found to be highly effective to produce aromatic polyamides and polyimides with the above desirable properties. $^{6-12}$

As part of an effort to develop organicsoluble high performance polyarylates with high glass transition temperatures, we have aimed at the synthesis of a new tetraphenylthiophene-containing diol monomer, 2,5-bis(4-hdroxyphenyl)-3,4-diphenylthiophene, as an alternative monomer to the polyarylate-forming diacid, 2,5-bis(4-carboxyphenyl)-3,4-diphenylthiophene. ${ }^{3}$ This article deals with the synthesis of the tetraphenylthiophenediol as well as of new tetraphenylthiophene-containing polyarylates derived from various aromatic dicarboxylic acid chlorides. Their properties are also described, which are compared with those of the tetraphenylated heterocycle-containing polyarylates reported previously. ${ }^{3-5}$

\section{EXPERIMENTAL}

\section{Materials}

Isophthaloyl chloride (IVa) and terephthaloyl chloride (IVb) were obtained commercially and distilled before use. 4,4'-Bibenzoyl chlo-

* To whom all correspondence should be addressed. 
ride (IVc), 2,6-naphthalenedicarbonyl chloride (IVd), 4,4'-oxybibenzoyl chloride (IVe), and 4,4'-sulfonyldibenzoyl chloride (IVf) were prepared by the reaction of the corresponding dicarboxylic acids with thionyl chloride and purified by distillation. All the solvents employed were purified by distillation before use.

\section{Monomer Synthesis}

2,5-Bis(4-methoxyphenyl)-3,4-Diphenylthiophene (II). 1,2-Bis(4-methoxybenzoyl)-1,2-diphenylethane (I), composed of two isomers with high melting point $\left(272-273^{\circ} \mathrm{C}\right)$ and low melting point $\left(148-149^{\circ} \mathrm{C}\right)$, was prepared in $76 \%$ total yield by the oxidative coupling of 4-methoxydeoxybenzoin using sodium ethoxide and iodine according to the procedure reported previously. ${ }^{5}$

A mixture of $46.0 \mathrm{~g}(0.102 \mathrm{~mol})$ of compound I with low melting point and $63.8 \mathrm{~g}(0.122 \mathrm{~mol})$ of the Lawesson reagent, 2,4-bis(4-methoxyphenyl)-1,3-dithia-2,4-diphosphetane-2,4disulfide, in $500 \mathrm{ml}$ of dry toluene was heated with stirring at $110^{\circ} \mathrm{C}$ for $5 \mathrm{~h}$. The reaction solution was evaporated to dryness under reduced pressure, and the solid residue was washed with acetic acid, followed by drying at $100^{\circ} \mathrm{C}$ under vacuum. Recrystallization from a mixture of methanol and acetone $(1: 1$ by volume) gave white needles (II); $\mathrm{mp} 208$ $209^{\circ} \mathrm{C}$. The yield was $29.3 \mathrm{~g}(64 \%)$. The IR spectrum (KBr) exhibited absorption bands at $2940-2820 \mathrm{~cm}^{-1}$ (methoxy C-H). Anal. Calcd. for $\mathrm{C}_{30} \mathrm{H}_{24} \mathrm{O}_{2} \mathrm{~S}: \mathrm{C}, 80.33 \%$; H, 5.39\%; S, $7.15 \%$. Found: C, $80.18 \% ; \mathrm{H}, 5.15 \% ; \mathrm{S}$, $7.23 \%$.

The reaction between compound I with high melting point and the Lawesson reagent under the similar conditions, followed by recrystallizations twice from a mixture of methanol and acetone, afforded the same product II in $32 \%$ yield.

2,5-Bis(4-hydroxyphenyl)-3,4-Diphenylthiophene (III). A mixture of $30.0 \mathrm{~g}(0.067 \mathrm{~mol})$ of compound II and $45 \mathrm{ml}$ of $47 \%$ hydrobromic acid in $500 \mathrm{ml}$ of glacial acetic acid was heated with stirring at $120^{\circ} \mathrm{C}$ for $7 \mathrm{~h}$ under nitrogen. The reaction solution was poured into 21 of water and the precipitate was collected. The product was washed thoroughly with water and dried at $100^{\circ} \mathrm{C}$ under vacuum. Recrystallizations twice from toluene afforded white needles (III); $\mathrm{mp} 236-237^{\circ} \mathrm{C}$. The yield was $16.3 \mathrm{~g}$ $(58 \%)$. The IR spectrum (KBr) showed an absorption band at $3300 \mathrm{~cm}^{-1}(\mathrm{O}-\mathrm{H})$. Anal. Cacld. for $\mathrm{C}_{28} \mathrm{H}_{20} \mathrm{O}_{2} \mathrm{~S}: \mathrm{C}, 79.97 \%$; H, 4.79\%; S, $7.63 \%$. Found: C, 79.65\%; H, 4.60\%; S, $7.65 \%$.

\section{Polymerization}

A typical example of the polycondensation is given below.

Polymer Ve from III and IVe by HighTemperature Solution Method. In a flask equipped with a stirrer, and gas inlet and outlet were placed $0.841 \mathrm{~g}(2.0 \mathrm{mmol})$ of III, $0.590 \mathrm{~g}$ $(2.0 \mathrm{mmol})$ of IVe, and $10 \mathrm{ml}$ of 1 -chloronaphthalene. The mixture was heated with stirring at $150^{\circ} \mathrm{C}$ for $1 \mathrm{~h}$, and the temperature was raised to $220^{\circ} \mathrm{C}$. The solution was further stirred for $15 \mathrm{~h}$ at that temperature. The hydrogen chloride evolved by the polycondensation was swept away by passing a slow stream of nitrogen. The resulting polymer was isolated by pouring the reaction solution into $300 \mathrm{ml}$ of methanol. The precipitated polymer was collected and dried at $100^{\circ} \mathrm{C}$ under vacuum, which weighed $1.23 \mathrm{~g}(96 \%)$. The inherent viscosity of the polymer was $0.67 \mathrm{dlg}^{-1}$ in sym-tetrachloroethane, measured at a concentration of $0.5 \mathrm{gdl}^{-1}$ at $30^{\circ} \mathrm{C}$. The IR spectrum (film) showed an absorption band at $1750 \mathrm{~cm}^{-1}(\mathrm{C}=\mathrm{O})$. Anal. Calcd. for $\left(\mathrm{C}_{42} \mathrm{H}_{26}\right.$ $\left.\mathrm{O}_{5} \mathrm{~S}\right)_{n}: \mathrm{C}, 78.49 \% ; \mathrm{H}, 4.08 \% ; \mathrm{S}, 4.99 \%$. Found: C, $78.71 \% ; \mathrm{H}, 3.79 \%$;, $4.89 \%$.

\section{Measurements}

IR spectra were recorded on a Hitachi EP-G3 spectrophotometer. Diffferential thermal analysis (DTA), thermogravimetry (TG), and differential scanning calorimetry (DSC) were 
performed with Shimadzu thermal analyzers DTA-40, TGA-40M, and DSC-41M, respectively, and the measurements were made in air or nitrogen at a flow rate of $50 \mathrm{ml} \mathrm{min}^{-1}$. The wide angle X-ray diffraction patterns were recorded with a Rigaku Denki XG X-ray diffraction apparatus using nickel-filtered $\mathrm{Cu}-K_{\alpha}$ radiation $(35 \mathrm{kV}, 50 \mathrm{~mA})$.

\section{RESULTS AND DISCUSSION}

\section{Monomer Synthesis}

A new heterocycle-containing bisphenol, 2,5-bis(4-hydroxyphenyl)-3,4-diphenylthiophene (III) was synthesized in three steps starting from 4-methoxydeoxybenzoin according to Scheme 1.

Recently the Lawesson reagent, 2,4-bis(4-methoxyphenyl)-1,3-dithia-2,4-diphosphetane2,4-disulfide, was used as a highly efficient substitute for classical sulfurizing agent of phosphorus pentasulfide for the synthesis of thiophenes from 1,4-dicarbonyl compounds. ${ }^{13}$ This reagent was successfully applied to the synthesis of 2,5-bis(4-methoxyphenyl)-3,4-diphenylthiophene (II) from 1,2-bis(4-methoxybenzoyl)-1,2-diphenylethane (I), prepared by the oxidative coupling of 4-methoxydeoxybenzoin. Although compound I has two isomers, high melting point and low melting point components, both isomers afforded the same thiophene compound II in moderate yields. The complete ring closure of compound I giving II was confirmed by the disappearance of the characteristic carbonyl band at 1669$1667 \mathrm{~cm}^{-1}$ in the IR spectrum, with retention of absorption bands due to methoxy group at $2940-2820 \mathrm{~cm}^{-1}$.

In the second step, the demethylation of compound II was effectively achieved by using strong protic acid such as hydrobromic acid, giving compound III in reasonable yields. Compound III exhibited an absorption band based on $\mathrm{O}-\mathrm{H}$ function at $3300 \mathrm{~cm}^{-1}$ in the IR spectrum, with the disappearance of the characteristic methoxy absorptions. The overall yield of the new bisphenol starting from compound I was approximately $35 \%$.

\section{Polymer Synthesis}

Tetraphenylthiophene-containing polyarylates $\mathbf{V}$ were synthesized by the polycondensation of bisphenol III with various aromatic dicarboxylic acid chlorides IVa-IVf, as shown in Scheme 2, by high temperature solution method. ${ }^{4,5}$

To find suitable polymerization conditions for the preparation of high molecular weight polyarylate Ve from III and IVe, the reaction variables such as reaction medium and temperature were investigated. Table I summarizes the results of the polycondensation, where the reaction time was fixed to $15 \mathrm{~h}$. The high temperature solution polycondensation
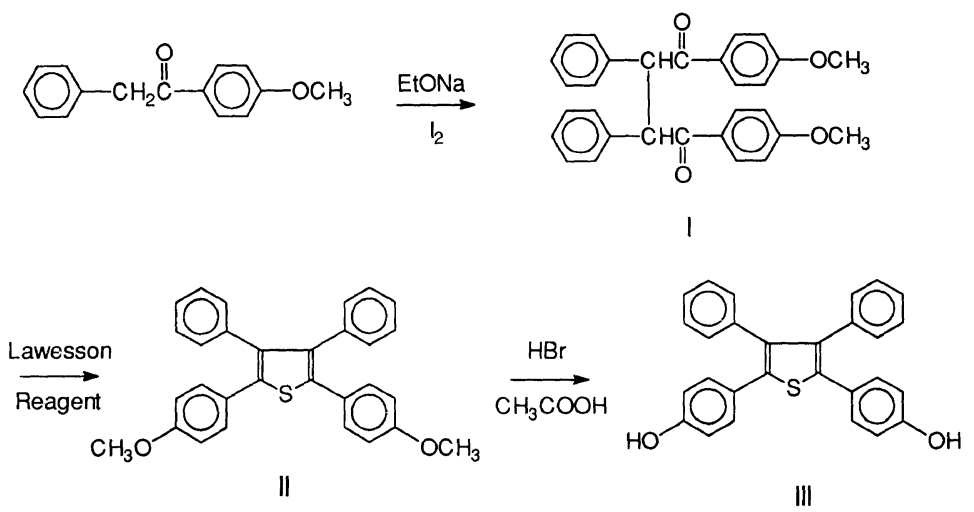

Scheme 1. 


\section{H.-J. JEONG et al.}

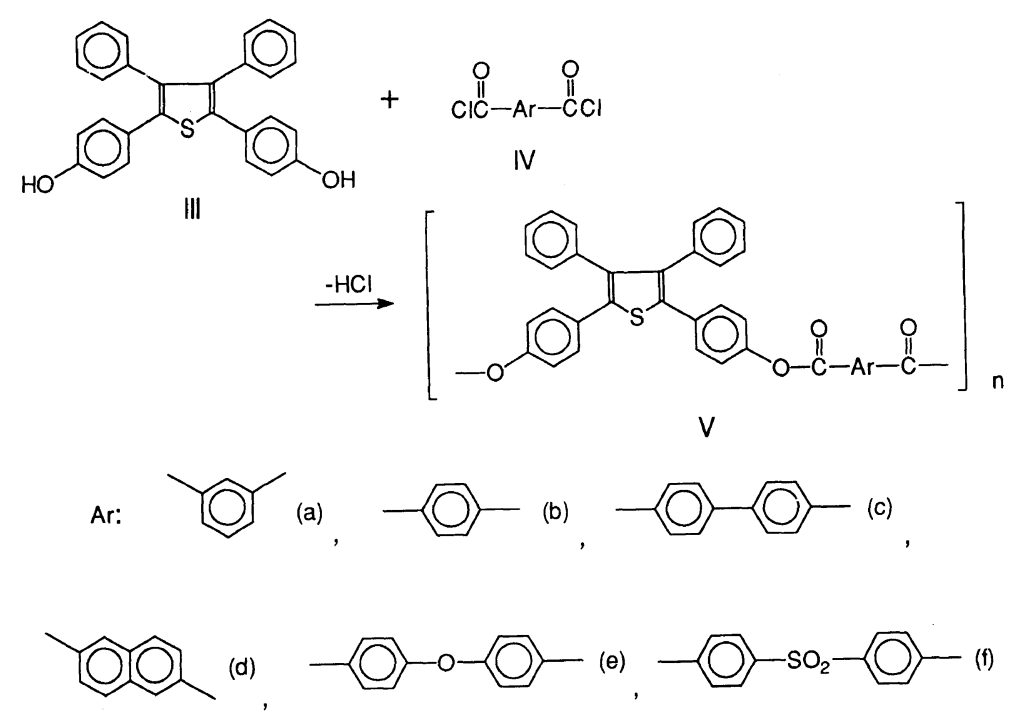

Scheme 2.

Table I. Synthesis of polyarylate Ve by high temperature solution method ${ }^{\mathrm{a}}$

\begin{tabular}{|c|c|c|c|}
\hline \multirow{2}{*}{ Reaction medium ${ }^{\mathrm{b}}$} & \multirow{2}{*}{$\begin{array}{c}\text { Reaction } \\
\text { temperature }\end{array}$} & \multicolumn{2}{|c|}{ Polymer } \\
\hline & & Yield & $\eta_{\mathrm{inh}}^{\mathrm{c}}$ \\
\hline $\mathrm{ml}$ & ${ }^{\circ} \mathrm{C}$ & $\%$ & $\mathrm{dlg}^{-1}$ \\
\hline $\mathrm{CN}(10)$ & 220 & 96 & 0.67 \\
\hline TCB (10) & 220 & 94 & 0.60 \\
\hline ODCB (10) & 180 & 86 & 0.72 \\
\hline PDCB (10) & 180 & 92 & 0.53 \\
\hline Tol (10) & 110 & 88 & 0.44 \\
\hline $\mathrm{CN}(5)+\mathrm{Py}(1.5)$ & 220 & 92 & 0.42 \\
\hline $\mathrm{TCB}(5)+\mathrm{Py}(1.5)$ & 220 & 93 & 0.49 \\
\hline $\mathrm{ODCB}(5)+\mathrm{Py}(1.5)$ & 180 & 88 & 0.84 \\
\hline PDCB (5) + Py (1.5) & 180 & 90 & 0.47 \\
\hline
\end{tabular}

a Polymerization was carried out with $2.0 \mathrm{mmol}$ of III and $2.0 \mathrm{mmol}$ of IVe in the reaction medium for $12 \mathrm{~h}$ under nitrogen.

b $\mathrm{CN}$, 1-chloronaphthalene; TCB, 1,2,4-trichlorobenzene; ODCB, o-dichlorobenzene; PDCB, $p$-dichlorobenzene, Tol, toluene; and Py, pyridine.

c Measured at a concentration of $0.5 \mathrm{~g} \mathrm{dl}^{-1}$ in sym-tetrachloroethane at $30^{\circ} \mathrm{C}$.

was carried out either in a high-boiling-point solvent alone, where the hydrogen chloride evolved during the reaction was swept away with a slow stream of nitrogen, or in the solvent in the presence of pyridine which acts as a hydrogen chloride acceptor. In the case of the polycondensation in the solvent alone, higher reaction temperature around $200^{\circ} \mathrm{C}$ tended to afford the polyarylate having higher inherent viscosity, mostly regardless of the kind of solvent. Although a mixture of the solvent and pyridine also effected the polymerization giving the polyarylate with reasonable inherent viscosity, the $o$-dichlorobenzene and pyridine system at $180^{\circ} \mathrm{C}$ was the most effective one to produce the polymer with the highest inherent viscosity of $0.84 \mathrm{dlg}^{-1}$, which was used in the further polymerizations.

A series of polyarylates were synthesized by the high temperature solution polycondensation of III with IVa-IVf, and the results are listed in Table II. In the case of the polycondensations with IVa-IVd, the precipitation of the polymers occurred during the reaction, and hence the inherent viscosities of the polyarylates $\mathbf{V a}-\mathbf{V d}$ could not be determined due to their insolubility in any organic solvents. Of course, the diacid chloride IVf yielded the polyarylate with inherent viscosity of $0.29 \mathrm{dlg}^{-1}$ by this method, in addition to polyarylate Ve. 
Table II. Synthesis of various polyarylates by high temperature solution method ${ }^{\mathrm{a}}$

\begin{tabular}{|c|c|c|c|c|}
\hline \multirow{3}{*}{$\begin{array}{l}\text { Diacid } \\
\text { chloride }\end{array}$} & \multicolumn{3}{|c|}{ Polymer } & \multirow{3}{*}{ Remarks $^{c}$} \\
\hline & \multirow{2}{*}{ Code } & Yield & $\eta_{\mathrm{inh}}^{\mathrm{b}}$ & \\
\hline & & $\%$ & $\mathrm{dlg}^{-1}$ & \\
\hline IVa & $\mathbf{V a}$ & 89 & - & $\mathbf{P}$ \\
\hline IVb & $\mathbf{V b}$ & 93 & - & $\mathbf{P}$ \\
\hline IVe & Ve & 93 & - & $\mathbf{P}$ \\
\hline IVd & Vd & 90 & - & $\mathbf{P}$ \\
\hline IVe & $\mathrm{Ve}$ & 88 & 0.84 & $\mathrm{~S}$ \\
\hline IVf & Vf & 86 & 0.29 & $\mathrm{~S}$ \\
\hline
\end{tabular}

a Polymerization was carried out with $2.0 \mathrm{mmol}$ of III and $2.0 \mathrm{mmol}$ of the diacid chloride in $5 \mathrm{ml}$ of $\mathrm{o}$ dichlorobenzene and $1.5 \mathrm{ml}$ of pyridine at $180^{\circ} \mathrm{C}$ for $15 \mathrm{~h}$ under nitrogen.

b Measured at a concentration of $0.5 \mathrm{gdl}^{-1}$ in symtetrachloroethane at $30^{\circ} \mathrm{C}$.

c Appearance of the polymerization mixture: P, precipitation of the polymer occurred during the reaction; S, homogeneous solution throughout the reaction.

These polymers were characterized by means of IR spectroscopy. The IR spectra of all the polymers exhibited a characteristic ester $\mathrm{ab}$ sorption band at $1750-1740 \mathrm{~cm}^{-1}$. The elemental analysis values of the polymers agreed quite well with the calculated values for the proposed polyarylates.

\section{Polymer Properties}

The solubility behavior of the tetraphenylthiophene-containing polyarylates were tested qualitatively, and the results are summarized in Table III. The polyarylates $\mathbf{V a}-\mathbf{V d}$ composed of rigid aromatic moieties were quite insoluble in any organic solvents, whereas the polymers Ve and Vf having flexible ether and sulfone connecting groups in the polymer backbones dissolved readily in a variety of organic solvents such as $N$-methyl2-pyrrolidone (NMP), o-chlorophenol, $m$ cresol, sym-tetrachloroethane, pyridine, and 1,4-dioxane. Polyarylate Ve only gave a transparent and flexible film by casting from the NMP solution. The solubility behavior of
Table III. Solubility of polyarylates ${ }^{\mathrm{a}}$

\begin{tabular}{lcccc}
\multicolumn{1}{c}{ Solvent } & \multicolumn{3}{c}{ Polymer } \\
\cline { 2 - 5 } & Va, Vb, Vc, Vd & Ve & Vf \\
\hline$N$-Methyl-2-pyrrolidone & - & ++ & ++ \\
$o$-Chlorophenol & - & ++ & ++ \\
$m$-Cresol & - & + & + \\
sym-Tetrachloroethane & - & ++ & ++ \\
Pyridine & - & + & ++ \\
1,4-Dioxane & - & + & + \\
Dimethyl sulfoxide & - & - & - \\
Acetone & - & - & - \\
Methano & & - & - & - \\
\hline
\end{tabular}

a Solubility: ++ , soluble at room temperature; + , soluble on heating; - , insoluble.

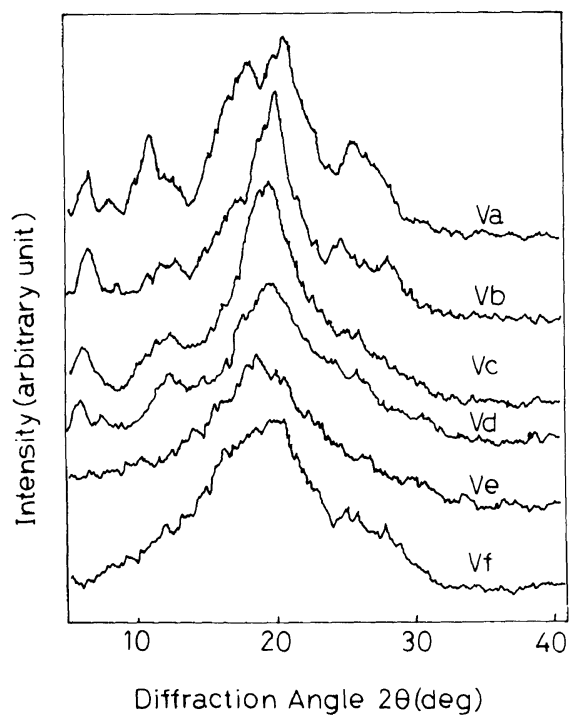

Figure 1. X-Ray diffraction diagrams of various polyarylates.

the tetraphenylthiophene-containing polyarylates markedly differed from that of the structurally related tetraphenylfuran- and tetraphenylpyrrole-based polyarylates, ${ }^{4,5}$ most of which were soluble easily in the above solvents.

Figure 1 shows the wide angle X-ray diffraction diagrams of the polyarylates. Polyarylates $\mathbf{V a}-\mathbf{V d}$ had several diffraction peaks, indicative of crystallinity, whereas polymers 
Table IV. Thermal properties of polyarylates

\begin{tabular}{|c|c|c|c|c|c|}
\hline \multirow{3}{*}{ Polymer } & \multirow{3}{*}{$\frac{T_{\mathrm{g}}^{\mathrm{a}}}{{ }^{\circ} \mathrm{C}}$} & \multirow{2}{*}{\multicolumn{2}{|c|}{$\frac{\text { Decomposition temperature }^{\mathrm{b}}}{{ }^{\circ} \mathrm{C}}$}} & \multicolumn{2}{|c|}{ Char yield ${ }^{c}$} \\
\hline & & & & \multicolumn{2}{|c|}{$\%$} \\
\hline & & In air & In nitrogen & In air & In nitrogen \\
\hline $\mathbf{V a}$ & 229 & 505 & 515 & 5 & 58 \\
\hline $\mathbf{V b}$ & 239 & 475 & 510 & 11 & 53 \\
\hline Ve & $-\mathrm{d}$ & 480 & 515 & 6 & 56 \\
\hline Vd & $\perp^{\mathrm{d}}$ & 475 & 515 & 7 & 53 \\
\hline Ve & 209 & 500 & 515 & 15 & 56 \\
\hline Vf & 260 & 510 & 520 & 20 & 58 \\
\hline
\end{tabular}

a By DSC at a heating rate of $20^{\circ} \mathrm{C} \mathrm{min}^{-1}$ in nitrogen.

b Temperature of $10 \%$ weight loss recorded by TG at a heating rate of $10^{\circ} \mathrm{C} \mathrm{min}^{-1}$.

c Char yield at $800^{\circ} \mathrm{C}$ by TG.

d $T_{\mathrm{g}}$ could not be detected.

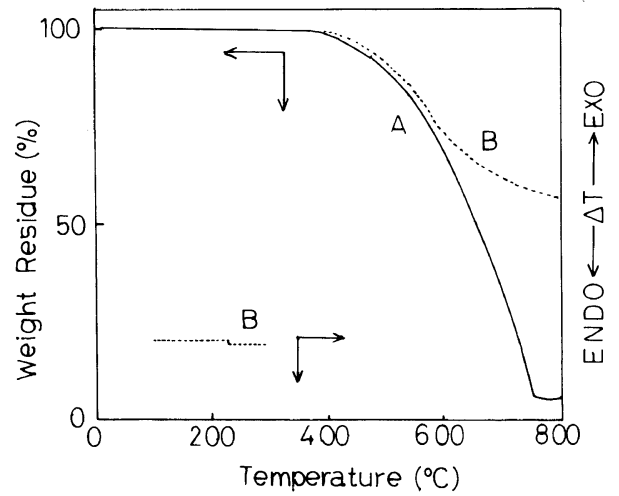

Figure 2. DTA and TG curves for polyarylate $\mathrm{Va}$ in air (A) and in nitrogen (B).

Ve and Vf had similar diffraction patterns with a broad peak at around $20^{\circ}$ in $2 \theta$, suggesting that they were semicrystalline. The crystalline nature of polymers $\mathbf{V a}-\mathbf{V d}$ was probably reflected in the insolubility of these polymers. In addition, the crystalline nature of the tetraphenylthiophene-contining polyarylates was quite different from the semicrystalline behavior of the tetraphenylfuran- and tetraphenylpyrrole-based polyarylates. ${ }^{4,5}$

The thermal behavior of the polyarylates was evaluated by means of DTA, TG, and DSC. Figure 2 exhibits the DTA and TG curves for typical polyarylate $\mathbf{V a}$, and the thermal properties of all the polyarylates are summarized in Table III. The glass transition temperatures $\left(T_{\mathrm{g}}\right)$ of the polyarylates except for Vc and Vd were in the range of $209-260^{\circ} \mathrm{C}$. All the polymers did not lose weight below $400^{\circ} \mathrm{C}$ in both air and nitrogen atmospheres, and their $10 \%$ weight losses were recorded at $475-510^{\circ} \mathrm{C}$ and $510-520^{\circ} \mathrm{C}$ in air and nitrogen, respectively, with $53-58 \%$ char yields at $800^{\circ} \mathrm{C}$ in nitrogen. In the present polyarylates, polymer Vf having polar sulfone connecting group had high $T_{\mathrm{g}}$ value than the other polyarylates. No appreciable difference in the thermal stability with respect to decomposition temperature and char yield was obsereved for the polyarylates with different compositions.

The present tetraphenylthiophene-containing polyarylates had a little higher $T_{\mathrm{g}}$ values and decomposition temperatures than the structuraly related tetraphenylfuran-based polyarylates, ${ }^{4}$ and were almost comparable to the tetraphenylpyrrole-derived polyarylates with respect to these thermal behavior. ${ }^{5}$ The difference in thermal stability is probably due to inherent stability between these three five-membered heterocyclic rings as discussed elsewhere. ${ }^{14}$ 


\section{CONCLUSIONS}

A new heterocyclic diol, 2,5-bis(4-hydroxyphenyl)-3,4-diphenylthiophene, was synthesized readily by the oxidative coupling of 4-methoxydeoxybenzoin giving 1,2-bis(4methoxybenzoyl)-1,2-diphenylethane, followed by thiophene ring formation and demethylation. The tetraphenylthiophenediol was subjected to the polycondensation with various aromatic diacid chlorides, producing the polyarylates having relatively high $T_{\mathrm{g}}$ values and good thermal stability.

\section{REFERENCES}

1. P. W. Morgan, "Condensation Polymers by Interfacial and Solution Methods," Interscience, New York, N.Y., 1965.

2. R. B. Seymour and G. S. Kirshenbaum, Ed., "High Performance Polymers: Their Origin and Deve- lopment," Elsevier, New York, N.Y., 1986.

3. M. Kakimoto, Y. S. Negi, and Y. Imai, J. Polym. Sci., A, Polym. Chem., 24, 1511 (1986).

4. H.-J. Jeong, M. Kakimoto, and Y. Imai, J. Polym. Sci., A, Polym. Chem., 29, 1293 (1991).

5. H.-J. Jeong, M. Kakimoto, and Y. Imai, J. Polym. Sci., A, Polym. Chem., in press.

6. Y. Imai, M. M. Maldar, and M. Kakimoto, J. Polym. Sci., Polym. Chem. Ed., 22, 2189 (1984).

7. M. Kakimoto, Y. S. Negi, and Y. Imai, J. Polym. Sci., Polym. Chem. Ed., 23, 1787 (1985).

8. Y. Imai, M. M. Maldar, and M. Kakimoto, J. Polym. Sci., Polym. Chem. Ed., 23, 1797 (1985).

9. H.-J. Jeong, Y. Oishi, M. Kakimoto, and Y. Imai, J. Polym. Sci., A, Polym. Chem., 28, 3293 (1990).

10. H.-J. Jeong, M. Kakimoto, and Y. Imai, J. Polym. Sci. A, Polym. Chem., 29, 39 (1991).

11. H.-J. Jeong, M. Kakimoto, and Y. Imai, J. Polym. Sci. A, Polym. Chem., 29, 767 (1991).

12. H.-J. Jeong, M. Kakimoto, and Y. Imai, J. Polym. Sci. A, Polym. Chem., 29, 1691 (1991).

13. D. R. Shridhar, M. Jogibhukta, P. S. Rao, and V. K. Handa, Synthesis, 1061 (1982).

14. H.-J. Jeong, A. Kobayashi, M. Kakimoto, and Y. Imai, Polym. J., 26, 373 (1994). 